\title{
Multidisciplinary Approach to an Extended Pressure Sore at the Lumbosacral Area
}

\author{
Sehoon Yoon ${ }^{1}$, Euicheol Jeong ${ }^{2}$, Hudson Alex Lázaro ${ }^{3}$ \\ ${ }^{1}$ Department of Plastic and Reconstructive Surgery, Seoul National University College of Medicine, Seoul; ${ }^{2}$ Department of Plastic Surgery, \\ SMG-SNU Boramae Medical Center, Seoul, Korea; ${ }^{3}$ Dr. Hudson Lázaro, Cirurgia Plástica Transplante Capilar, Pará de Minas, Brazil
}

\begin{abstract}
A pressure sore wound is often extensive or complicated by local infection involving adjacent soft tissue and bone. In this case, a regional flap after simple debridement is not adequate. Here, we present a case of an extensive pressure sore in the sacral area with deep tissue infection. A 43-year-old female patient with a complicated sore with deep tissue infection had a presacral abscess, an iliopsoas abscess, and an epidural abscess in the lumbar spine. After a multidisciplinary approach performed in stages, the infection had subsided and removal of the devitalized tissue was possible. The large soft tissue defect with significant depth was reconstructed with a free latissimus dorsi musculocutaneous flap, which was expected to act as a local barrier from vertical infection and provide tensionless skin coverage upon hip flexion. The extensive sacral sore was treated effectively without complication, and the deep tissue infection completely resolved. There was no evidence of donor site morbidity, and wheelchair ambulation was possible by a month after surgery.
\end{abstract}

Keywords Pressure ulcer / Osteomyelitis / Epidural abcess / Psoas abscess
Correspondence: Euicheol Jeong Department of Plastic Surgery, SMGSNU Boramae Medical Center, 20 Boramae-ro 5 gil, Dongjak-gu, Seoul 07061, Korea

Tel: $+82-2-870-2859$

Fax: $+82-2-870-2331$

E-mail: ejeong.md@gmail.com

No potential conflict of interest relevant to this article was reported.

Received: 15 Apr $2016 \bullet$ Revised: 20 Sep $2016 \bullet$ Accepted: 28 Sep 2016

pISSN: 2234-6163 • elSSN: 2234-6171 • https://doi.org/10.59909/aps.2016.43.6.586• Arch Plast Surg 2016;43:586-589

\section{INTRODUCTION}

Regional flaps are usually the first choice in pressure sore reconstruction, providing the theoretical advantage of effectively eliminating dead space and providing good blood supply to overlying soft tissues, which improves resistance to infections. However, if the wound is extensive or complicated by infection, local flap coverage may be inadequate. Here, we present a case of an extensive pressure sore in the sacral area with deep tissue infection. A multidisciplinary approach was performed in stages, and the large soft tissue defect was reconstructed by free-flap transfer.

\section{CASE}

A 43-year-old female patient had a history of spinal tuberculosis
(4.5 years ago), and became paraplegic after treatment. A few years later, a sacral sore developed due to her bed-ridden state. Conservative management at other hospitals was not effective, and the wound became aggravated.

At admission, she had a $20-\mathrm{cm} \times 10-\mathrm{cm}$ grade IV ulcer at the sacrum, with exposure of the sacral bone (Fig. 1). Due to chronic diarrhea, severe malnutrition was observed in the laboratory results. With leukocytosis, fever, and low blood pressure, the patient had the diagnostic signs of sepsis. Computed tomographic (CT) and magnetic resonance (MR) scans revealed sacrococcygeal osteomyelitis as well as a presacral abscess, an iliopsoas abscess, and an epidural abscess in the lumbar spine (Fig. 2).

Intravenous antibiotics were immediately started with a broadspectrum empirical regimen. Methicillin-resistant Staphylococcus aureus was isolated from the wound and selective antibiotics 


\section{Fig. 1. Preoperative sacral wound after debridement}

The sacral defect was oval in shape and measured $20 \mathrm{~cm} \times 10 \mathrm{~cm}$ with an active infection. The lower half of the sacral bone was partially removed and the remaining portion was exposed in the center of the ulcer.

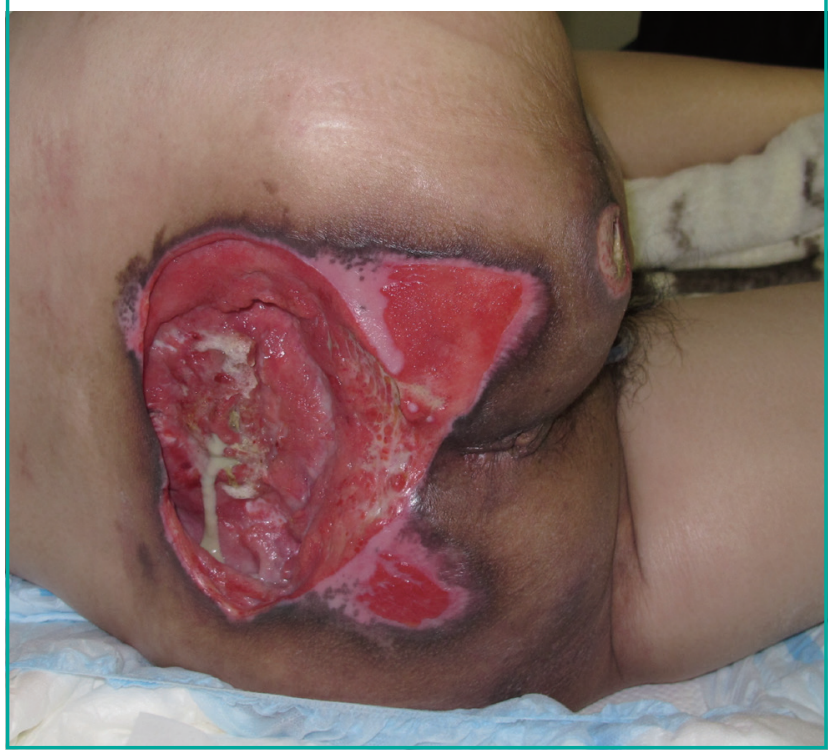

\section{Fig. 2. Preoperative MRI exam}

An MR image (T2-enhanced) showed a complicated pressure sore with a presacral abscess (yellow arrowhead), a psoas abscess (red arrow), and an epidural abscess (red arrowhead). MRI, magnetic resonance imaging.

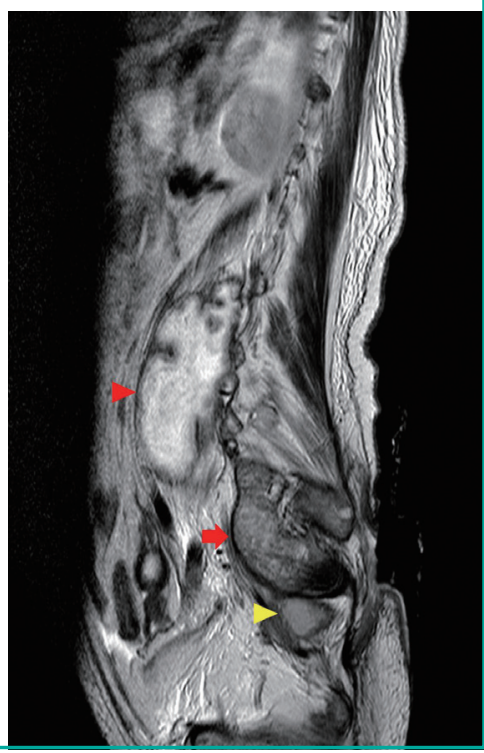

were used until the second week after the final operation. Diarrhea was controlled with medication, and total parenteral nutrition was administered before surgery for the correction of the patient's nutritional deficiencies.

Since the patient was initially too unstable to tolerate long surgery, several steps of treatment were planned. The presacral abscess and iliopsoas abscess were percutaneously drained with CT-guided catheterization (Fig. 3). After the patient's condition partially improved, open laminectomy was possible and the epi-

\section{Fig. 3. Preoperative vascularity at recipient site}

Computed tomography angiography verified patency of the right superior gluteal artery (yellow arrow).

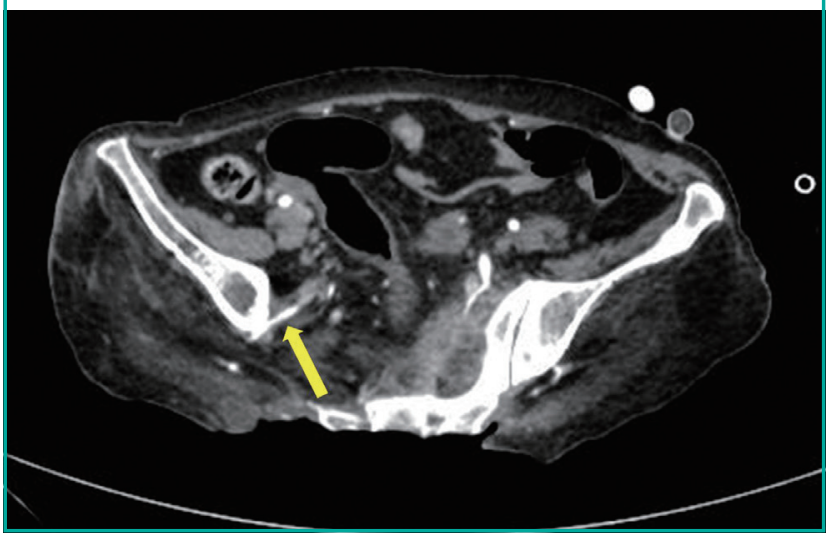

Fig. 4. Intraoperative photo after microscopic anastomosis

The latissimus dorsi myocutaneous free flap pedicle was anastomosed to the recipient vessels, the superior gluteal artery, and its venae comitantes, after the muscle-splitting technique was performed.

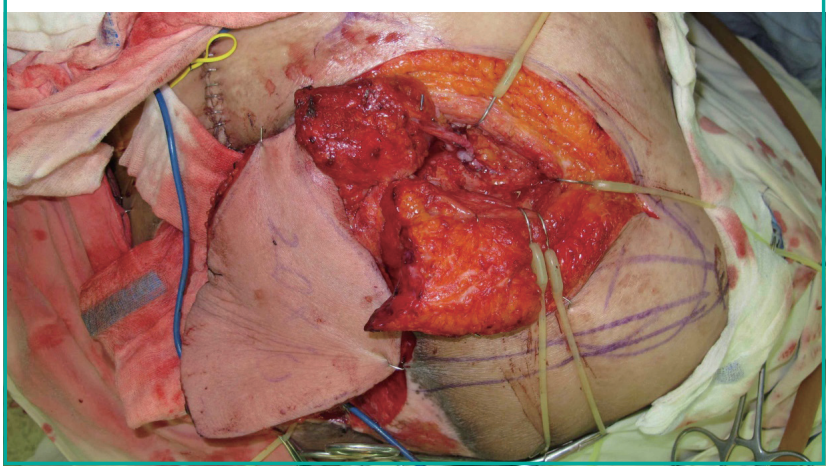

dural abscess, sequestrum in the remnant sacrum, and unhealthy granulation tissue were removed. After local inflammation subsided, delayed reconstruction was planned a week later. Before the operation, vessel parameters were checked at the recipient and donor site area by CT angiography.

Using a latissimus dorsi myocutaneous free flap in the right flank, the soft tissue defects of the sacral wound were repaired. The vascular pedicle and thoracodorsal vessels were anastomosed to the right superior gluteal artery and its venae comitantes, which were found by splitting the gluteus maximus muscle fibers. The muscular part of the flap was inset into the deficit area on the sacral bone and lumbar spine (Fig. 4). The donor site of the flap was repaired by primary closure and a split-thickness skin graft. The total operation time was 6 hours and 20 minutes.

The operative wound healed without complication, and sequential advancement of positions was performed. Until 22 days after the surgery, only prone and lateral decubitus positions were allowed. By gradually increasing the duration of the sitting 


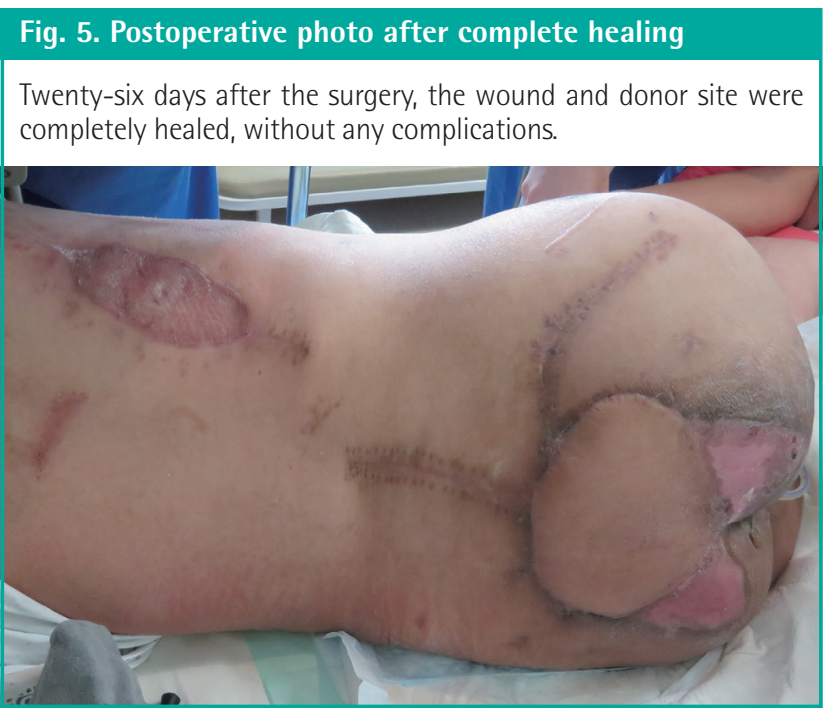

position by steps, wheelchair ambulation was possible on postoperative day 26. Flap color and vascular patency were well preserved and improvement in the soft tissue infection was observed in follow-up CT imaging. At 46 days after surgery, the patient was discharged, and no complications such as wound dehiscence or necrosis of the flap had occurred at a 3-month postoperative follow-up visit (Fig. 5). Donor site morbidity was minimal, with no range of motion impairment of the shoulder joint.

\section{DISCUSSION}

Patients who are chronically ill and frequently debilitated have accompanying nutritional deficiencies. These lead to weight loss, a negative nitrogen balance, poor wound healing, and immunosuppression, all of which strongly correlate with pressure sores [1]. In addition, immobility leads to increased pressure, friction, and shear, which are causative factors of pressure sores.

As in this case, severe sores are often accompanied by deepseated infections. These infections require early management before surgery, which should be multidisciplinary, involving spinal surgeons, radiologists, and infectious disease specialists.

Empirical antibiotics should be started at admission, and after identification of the infectious agent, appropriate antibiotics should be administered for at least 6 weeks. Before the reconstructive surgery, a localized infection such as an abscess pocket should be checked thoroughly and total debridement of necrotic or devitalized tissue should be performed. An MR scan is the most sensitive and specific test for the diagnosis of spinal epidural abscess, presacral abscess, and vertebral osteomyelitis $[2,3]$. Neurosurgical decompression (i.e., laminectomy, hemilaminectomy or interlaminar fenestration) is known to be the treatment of choice for epidural abscess [4]. A CT scan is useful as a guiding tool for percutaneous drainage of presacral abscesses, using pre-existing radiography findings. Targeted antibiotics may be sufficient to treat abscesses up to $60 \mathrm{~mm}$, but aspiration or open drainage of these abscesses seems to be more predictive of a positive outcome [5].

After control of the soft tissue infection, reconstructive surgery is considered. If the soft tissue defect cannot be closed with a local flap because no more regional tissue is available, a free flap should be considered [6]. However, finding a suitable recipient vessel is a significant issue for free flap reconstruction, and Park [7] overcame this difficulty through a muscle-splitting approach to access the recipient vessel without causing damage, which allowed a sufficient pedicle length to be obtained. For the sacral area, the superior gluteal vessel is large in caliber and constant, with numerous branches lying in proximity to the lesion, which makes it a reliable recipient vessel [8].

In this patient, the ultimate goals were a sitting position adequate for wheelchair ambulation and wound tension resilient to hip flexion. The wide skin paddle of the latissimus dorsi muscle flap imposed no burden on incremental increases in adjacent tissue tension. The muscle portion was also expected to be a local barrier for wounds, preventing the vertical spread of infection [9], as well as relieving the pressure in the sitting position, which is crucial for flap survival.

Rasmussen and Bennett [10] stated that the neovascularization at cutaneous free flaps is almost complete as soon as 10 to 14 days postoperatively. This enables early wheelchair ambulation and early rehabilitation, starting less than a month after surgery.

By means of a multidisciplinary approach, a complicated pressure sore with sacrococcygeal osteomyelitis, presacral and iliopsoas abscesses, and an epidural abscess in the lumbar spine was effectively treated, and delayed reconstruction with a latissimus dorsi myocutaneous free flap was successful, with satisfactory long-term results.

\section{REFERENCES}

1. Kwon R, Janis JE. Pressure sore. In: Neligan P, editor. Plastic surgery. Philadelphia: Elsevier Saunders; 2013. p.352-82.

2. Jarvik JG, Deyo RA. Diagnostic evaluation of low back pain with emphasis on imaging. Ann Intern Med 2002;137:58697.

3. Ricci MA, Meyer KK. Psoas abscess complicating Crohn's disease. Am J Gastroenterol 1985;80:970-7.

4. Sendi P, Bregenzer T, Zimmerli W. Spinal epidural abscess in clinical practice. QJM 2008;101:1-12. 
5. Cantasdemir M, Kara B, Cebi D, et al. Computed tomography-guided percutaneous catheter drainage of primary and secondary iliopsoas abscesses. Clin Radiol 2003;58:811-5.

6. Lemaire V, Boulanger K, Heymans O. Free flaps for pressure sore coverage. Ann Plast Surg 2008;60:631-4.

7. Park S. Muscle-splitting approach to superior and inferior gluteal vessels: versatile source of recipient vessels for freetissue transfer to sacral, gluteal, and ischial regions. Plast Reconstr Surg 2000;106:81-6.
8. Park S, Koh KS. Superior gluteal vessel as recipient for free flap reconstruction of lumbosacral defect. Plast Reconstr Surg 1998;101:1842-9.

9. Bruck JC, Buttemeyer R, Grabosch A, et al. More arguments in favor of myocutaneous flaps for the treatment of pelvic pressure sores. Ann Plast Surg 1991;26:85-8.

10. Rasmussen DL, Bennett JE. Acquisition of vascular supply by cutaneous flaps in pigs. Surg Forum 1976;27:568-70. 